\title{
Editorial
}

\section{International stations or international research?}

$\mathrm{T}$ here has been much adverse comment over recent years, especially by those with little practical Antarctic knowledge, of the apparent need to establish a national Antarctic station in order to gain Consultative Status at Treaty Meetings. Why, cry all these querulous voices, can't you co-operate more effectively, stop establishing new national stations and share your stations? Why are there not international rather than national stations in the Antarctic - surely that should be the aim of the Treaty Parties?

Power to question without the responsibility to act - if only life was as simple as our critics would have us believe! They appear to assume that the Antarctic organizations themselves and the scientists involved have never considered this question. Of course it has been considered again and again, but the practical problems inherent in establishing such an approach are considerable and no amount of wishing or arm waving will make them go away.

The first and most important fact is that many stations are effectively international anyway in their scientific activities. To take a few examples from this last season - the British programme had scientists from nine other countries working there, the Italian station had eight other nationalities, the US programme hosted scientists from over 15 countries. The second important point is that the Treaty has accepted a new interpretation of the qualification procedure which does away with the apparent need to establish a station. The recent confirmation of the Netherlands as a Consultative Party confirms this.

Why then are there no international stations? Some existing stations are more international than others. Jubany, for example, is jointly run by Argentina and Germany. Arctowski has previously welcomed a large contingent from the Netherlands and the new station at Dome $C$ is to be jointly run by France and Italy. There have been inconclusive discussions for years about the possibility of establishing a completely international station on the plateau but no real progress. The real reason why international stations are so hard to establish is not scientific but political. Each country has established very different bureaucratic systems for funding its Antarctic research and choosing which science projects to support. There are also the direct political reasons for supporting Antarctic science and cultural differences in approaching organization of logistics which manifest themselves in variety of ways. Aspects of control, responsibility, investment and choice are often difficult to address within the programme of a single country - how much more difficult to resolve at the international level.

And what goals would be attainable by the "International Station" but not by the present system? Some non-Antarctic countries see important political goals but in my view there are no scientific ones. The time and effort spent trying to reach agreement on this international concept would be better invested in continuing to develop the present system, minimizing duplication and poor quality science and maximizing collaborations and the opportunities for important science. Where joint agreements appear fruitful then let them be developed but let us not be distracted from science by this political blind alley.

There are some countries without permanent bases whose scientists are reliant on research opportunities offered by those countries supporting permanent bases and polar research ships. These research places are expensive. I wonder, however, how many are paying the real economic costs of supporting their visiting scientists in Antarctica and how much they are relying on the generosity of the other nations? Is this fair and conducive to lasting co-operation?

D W H WaLTON 